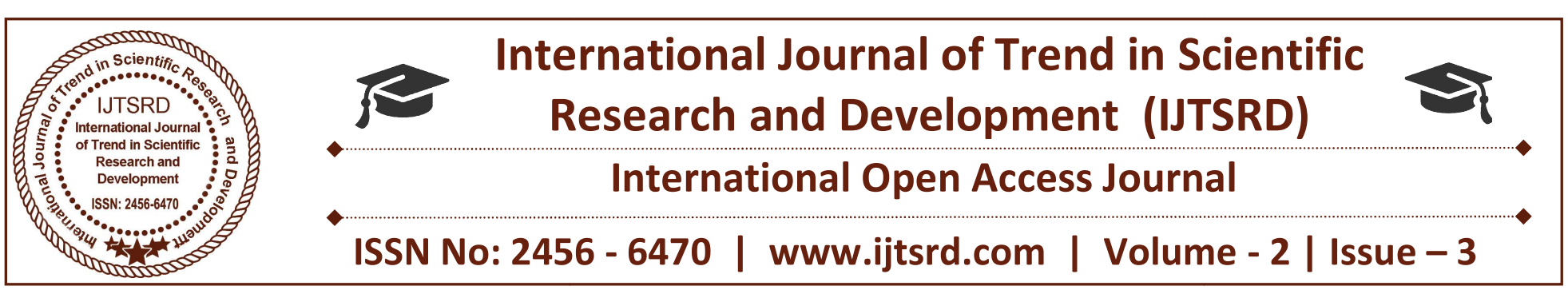

\title{
Callus culture of Azadirachta indica employing its stem
}

\author{
Saurish Sarkar \\ Research Scholar, Jharkhand Rai University, Ranchi, India
}

\begin{abstract}
Azadirachtin,an insecticidal active ingredient present in neem tree i.e.Azadirachta indica A. Juss.seeds and they varies considerably due to environmental factors also for genetic reasons. Furthermore, the tree does not grow in moderate climates and their germination ratio is very less. It seems appropriate, therefore, to employ tissue culture techniques for the production of Azadirachtin in order to obtain constant amounts of standardized quality. Here we try to create callus, an unspecialized, unorganized, growing and dividing mass of cells through which mass cultivation further initiate. The best media generally we use is MS Media along with different concentrations of hormones i.e. Auxins(BAP) and Cytokinin (Kinetin), employing Azadirachta indica stem.
\end{abstract}

Keywords: Micro propagation, Callus, MS media, Auxin, Cytokinin, Root, Shoot

\section{INTRODUCTION}

Neem or Azadirachta indica, is a versatile Indian tree having great importance. Neem is an untapped natural resource as like as its genetic potential is concerned. It is one of the most valuable arid zone trees belonging to the family Meliaceae. A native of dry forest areas of India and the subcontinent, Azadirachta indica is widely cultivated in the arid and nutrient deficient regions of India and Africa. Besides being a popular avenue tree with a large crown and the wood of neem has been used as timber for furniture, house building, and other domestic as well as agricultural tools. The timber is reported to work well with hand and machine tools (Tewari 1992). Its wood resembles to teak wood in strength and is more resistant to shock, fungi and insect attack; it is also immune to termites and durable even outdoors (Thengane, 1995). Neem tree is known to increase the soil fertility. It has huge

water holding capacity and the tree has a unique property of calcium mining which changes the acidic soil into neutral. The tree is resistant to high temperatures and drought and has been employed for afforestation of dry localities, reforesting bare ravines and checking soil erosion (Gill et al., 1996). Beside of that various parts of the neem tree, particularly leaves, bark and seeds have been traditionally used in India in ayurvedic medicines. The seed oil has been used as anti malarial, anthelminthic, vermifuge, antiseptic, and antimicrobial, it is also known to cure various skin disorders.

Azadirachta indica A. Juss is famous for its insecticidal properties and neem seed extracts show great potential as environmentally acceptable bioinsecticides for crop protection (Jacobson 1988; Mordue (Luntz) and Blackwell 1993; Schmutterer 1990). The first commercial neem insecticide, Margosan-O, was registered by the Environmental Protection Agency (EPA) in 1985 for use on non-food crops (Jacobson 1988; Larson 1993) and from then the number of commercial and experimental neem insecticides has increased markedly with Azatin (Agridyne Technologies, USA) recently receiving EPA approval for use on food crops (Johnson et al. 1994). Neem having these properties due to the presence of several bioactive compounds; the most prominent one being Azadirachtin. Unfortunately, the germination ratio is very less as compare to other plants of Meliaceae family.

In order to meet the economic demand of the neem tree, an efficient propagation technique is required through which we could get a large quantities and good quality of planting materials. Vegetative propagation of an adult neem tree by conventional 
methods is difficult (Kaushik 2002). Therefore, it is normally grown from seeds but the seeds are of recalcitrant type; they loose its viability within 2-3 weeks (Mohan et al. 1996). Propagation by seeds is also undesirable because of the highly heterozygous nature of the plant owing to cross-pollination and enormous heterozygosity. Moreover, the reproductive phase in neem normally begins after 5 years of seed propagation (Koul et al. 1990 and Schmutterer 1995). So, one has to wait for a long time to obtain seeds and fruits.

Micro propagation is a method which would provide the best means for mass clonal propagation of selected elite trees, where as tissue culture is the only methodology that can produce a large quantity of clonal plants in short time with high phyto sanitary quality (Silva et al. 2014). Azadirachtin, which shows anti feedant and growth-regulatory activities against a wide range of insects, is the major bioactive chemical present in neem kernels (Ley et al. 1993) with the average yield from seeds being around 2-4 mg g-1 dry weight seed kernels (National Research Council 1992). Azadirachtin yields are however, variable, being dependent on plant ecotype and environment (Ermel et al. 1986; Singh 1986). The development of simple and rapid methods for the production of uniform neem populations with high Azadirachtin yields is desirable.

To meet the economic demand of the neem tree, an efficient and effective propagation technique is required which could result in large quantities and good quality of planting materials. Vegetative propagation of an adult neem tree by conventional methods is difficult (Kaushik 2002). So,it is normally grown from seeds but the seeds are of recalcitrant type; they loose viability within 2-3 weeks (Mohan et al. 1996). Propagation by seeds is also undesirable because of the highly heterozygous nature of the plant owing to cross-pollination and enormous heterozygosity. Moreover, the reproductive phase in neem normally begins after 5 years of seed propagation (Koul et al. 1990 and Schmutterer 1995). So, one has to wait for a long time to obtain seeds and fruits. Micro propagation method would provide the best means for mass clonal propagation of selected elite trees in a short period of time. Due to the difficulty in germinating neem seeds, in vitro propagation techniques are very important for this plant, as they can allow for selection and rapid multiplication of high-value phenotypes (Quraishi et al. 2004). In vitro propagation of neem has been reported via both direct (Ramesh and Padhya 1990; Joshi and Thengane 1996; Zypman et al. 1997; Eeswara et al. 1998) and indirect (Zypman et al. 1997; Salvi et al. 2001) morphogenetic pathways.

In present context, the main objective of this experiment is to establish a procedure which can be used routinely to produce complete micro propagated plantlets from neem using stem i.e. Apical and lateral meristem explants of plants from mature trees.

The culture medium mostly used for the in vitro cultivation of Azadirachta indica is the Murishage and Skoog medium (Murishage and Skoog.1962).

\section{Materials and methods:-}

\section{Plant material}

Simply cutting of axiallary or lateral stem of neem approximately size of 4-5 centimeters collected from campus of Adithya biotech lab, Raipur. After collection of stem along with the leaves immediately dipped into beaker having distilled water in it. Which helps to keep the plant away from any kind of infection.

\section{Explant preparation}

Explant collected from field dipped in distill water

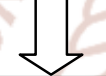

Cutting of leaves from the desired stem after washing under running tap water

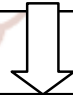

Wash the explant with the help of Teepol $(0.2 \%)$

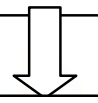

Keep in the beaker containg 70\% Ethanol for 3 minutes

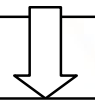

After 3 time washing with double distill water treated with Bavistin $(0.1 \%)$ mixed with antibiotic $(250 \mathrm{mg}$ for $500 \mathrm{ml}$ )

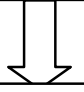

Again washing 3 times with double distill water treated with $0.1 \%$ Mercuric chloride for 5 minutes and wash it thoroughly with distill water 


\section{Nutrient Media}

The cuttings were slightly trimmed at both ends to expose the fresh tissue and grown firstly on Murishage and Skoog (MS medium), whose composition are as follows and then secondly on MS medium with plant hormones Auxins and Cytokinin of different ratios.

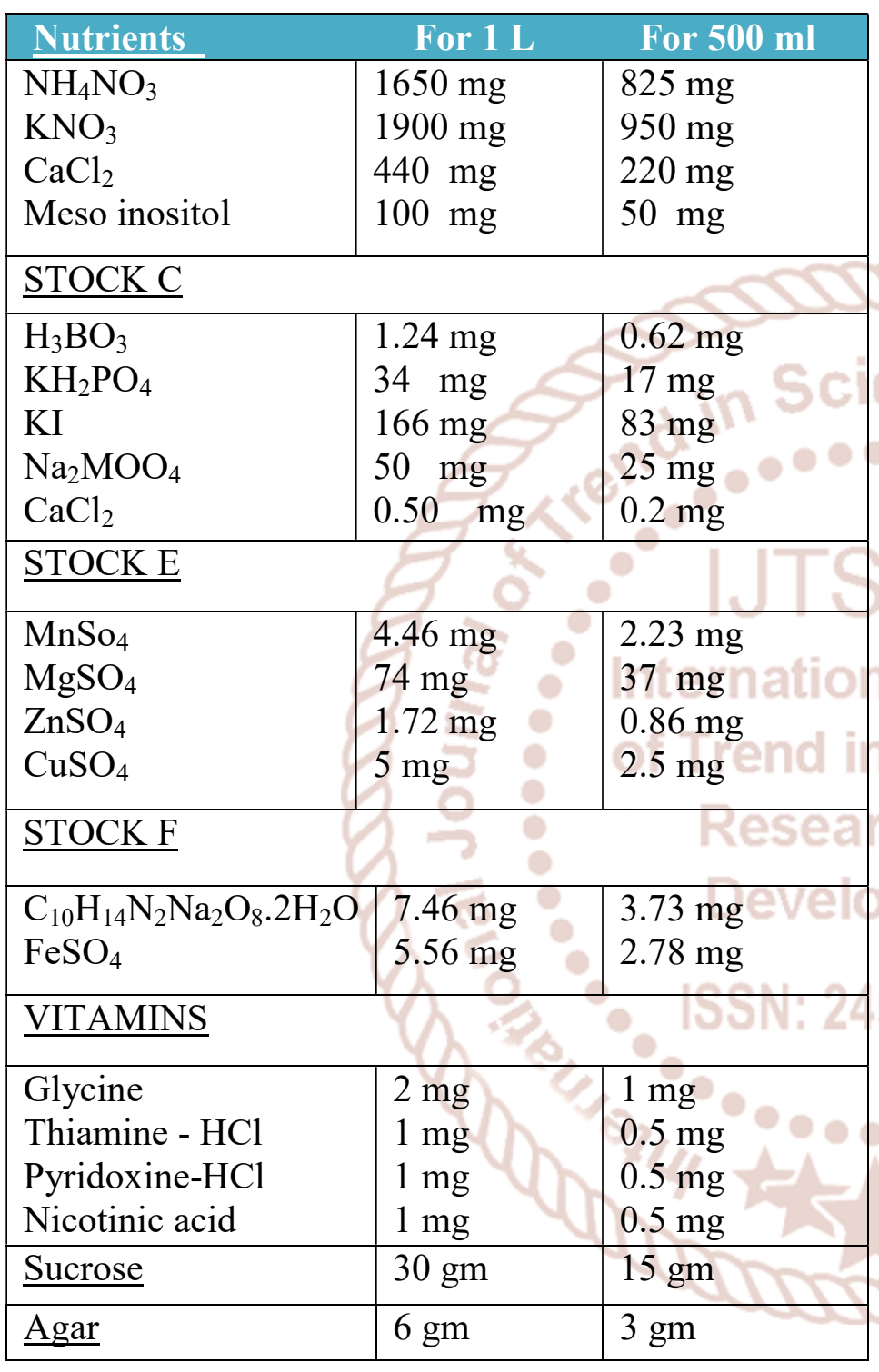

$\mathrm{pH}$ must be maintained 5.80 and balanced by the help of $1 \mathrm{~N} \mathrm{NaOH}$ and $1 \mathrm{~N} \mathrm{HCl}$. The explants kept in the incubation chamber temperature must be $25 \pm 2{ }^{\circ} \mathrm{C}$ and 16 hours in light. Later after 2 weeks for secondary culture explants were transferred into MS medium containing various ratio of Auxin and Cytokinin i.e. IBA: Kinetin, in different ratios. After 4-5 weeks plants were gradually moved away from lab and transferred to cocoa pit in a shed house at $25 \pm 2$ ${ }^{0}$ C.After 2 and half months they were shifted to a area under natural conditions.

\section{$\underline{\text { Sterilization process }}$}

Contamination of Azadirachta indica explants were a major trouble during incubation of culture. Specially in the month of June -August, monsoon season in India, where the chances of contamination increases around to $100 \%$ therefore normally researcher prefer the month of March-May.. Before inoculation the laminar airflow is cleaned by $70 \%$ methanol, each and every instrument like scalpel, forceps dipped in $70 \%$ methanol. We used new blade for scalpel regarding inoculation. We sterilize plastic sheets and media i.e. bottles containing MS media and test tubes in autoclave at $121{ }^{\circ} \mathrm{C}$ at $15 \mathrm{psi}$ for 20 minutes .After sterilization of media it was kept in inoculation chamber for 1-2 days to check whether any kind of infection is present or not. After 1-2 days we started the process of inoculation and on the day of inoculation once again sterilize the instruments use during the inoculation.

\section{Callus induction}

Azadirachta indica stems were used as explant material.During the process development of callus from the stem, a white color undifferentiated mass was developed.The callus initiated from stem grows rapidly within two weeks.After two weeks sufficient callus which was later sub culture on MS medium supplemented with lower dosage of Auxin and Cytokinin i.e IBA:Kinetin On this medium optimal callus growth was obtained and callus was maintained subsequently on this callus multiplication medium. Cultures were incubated in dark.

\section{Hardening and Acclimatization of in vitro} regenerated plantlets

After one week of transfer of in vitro raised plantlets to poly house. Bottles containing plantlets were the shifted from the pad section towards the fan section to provide growing conditions of low humidity (50 $60 \%)$ and high temperature $\left(30 \pm 2^{\circ} \mathrm{C}\right)$. after 4 weeks, acclimatized plantlets were transferred to poly begs containing a mixture of soil + sand + FYM (Farm yard manure) (2:1:0.5). such plantlets were kept in the poly house for 3- 4 weeks and then shifted to agro shade house then open environment.

\section{Result and discussion:-}

After inoculation wait for few days to observe whether the explants contaminated by pathogens like fungi or rarely by bacteria. Those test tubes get 
International Journal of Trend in Scientific Research and Development (IJTSRD) ISSN: 2456-6470

contaminated taken out from the incubation chamber and decontaminated by using autoclave and wash thoroughly by using detergent followed by dip in carbolic acid for 24 hours. Total 10 test tubes were taken each containing equal amount of MS Media

\begin{tabular}{|c|c|c|c|}
\hline Protocol I (MS Media) & $\begin{array}{l}\text { After } 2 \text { days } \\
\text { (contamination observed) }\end{array}$ & $\begin{array}{l}\text { After } 5 \text { days } \\
\text { (contamination observed) }\end{array}$ & $\begin{array}{l}\text { After } 7 \text { days } \\
\text { (contamination } \\
\text { observed) }\end{array}$ \\
\hline Test tube no. 1 & $\mathbf{N}$ & $\mathbf{N}$ & $\mathbf{Y}$ \\
\hline Test tube no. 2 & $\mathbf{N}$ & $\mathbf{N}$ & $\mathbf{N}$ \\
\hline Test tube no. 3 & $\mathbf{Y}$ & - & - \\
\hline Test tube no. 4 & $\mathbf{N}$ & $\mathbf{Y}$ & - \\
\hline Test tube no. 5 & $\mathbf{N}$ & $\mathbf{N}$ & $\mathbf{N}$ \\
\hline Test tube no. 6 & $\mathbf{Y}$ & - & - \\
\hline Test tube no. 7 & & $\mathbf{Y}$ & - \\
\hline Test tube no. 8 & $\mathbf{N}$ & $\mathbf{N}$ & $\mathbf{N}$ \\
\hline Test tube no. 9 & $\mathbf{N} 0$ & & - \\
\hline Test tube no.10 & $\mathbf{N}$ & 2103 & $\mathbf{Y}$ \\
\hline Control & $\mathbf{N}$ & $\mathbf{N}_{\text {Scientific }}$ & $\mathbf{N}$ \\
\hline
\end{tabular}

Out of 10 test tube only 4 test tube survived, the survival percentage is $40 \%$. The experiment was conducted in month of June, monsoon season in India. Huge growth of fungus observed in most of the tubes within few days of incubation. After 2 weeks the callus were transferred into media containing Cytokinin for shooting., we use Kinetin $150 \mu 1$ for $1000 \mathrm{ml}(15 \mu \mathrm{l}$ for $100 \mathrm{ml})$

\begin{tabular}{|l|l|l|l|l|l|l|l|l|}
\hline Test tube & \multicolumn{3}{|l|}{ Nunber of leaves observed } & \multicolumn{3}{c|}{ Number of Stem observed } \\
\hline & Day 1 & $\begin{array}{l}\text { Day } \\
7\end{array}$ & Day 10 & Day 14 & Day 1 & Day 7 & Day 10 & Day 14 \\
\hline Test tube No. 2 & 0 & 0 & 1 & 1 & 0 & 0 & 1 & 1 \\
\hline Test tube No. 5 & 0 & 0 & 1 & 2 & 0 & 1 & 1 & 2 \\
\hline Test tube No. 8 & 0 & 0 & 1 & 1 & 0 & 0 & 1 & 1 \\
\hline
\end{tabular}

After 2 weeks they transferred into Auxin containing mediafor rooting purpose and here we used IBA $15 \mu 1$ for $100 \mathrm{ml}$.

\begin{tabular}{|l|l|l|l|l|l|}
\hline & \multicolumn{5}{|c|}{ Number of roots observe } \\
\hline & Day 1 & Day 3 & Day 7 & Day 10 & Day 14 \\
\hline Test tube No. 2 & 0 & 1 & 2 & 4 & 10 \\
\hline Test tube No. 5 & 0 & 0 & 1 & 3 & 7 \\
\hline Test tube No. 8 & 0 & 1 & 3 & 5 & 8 \\
\hline
\end{tabular}



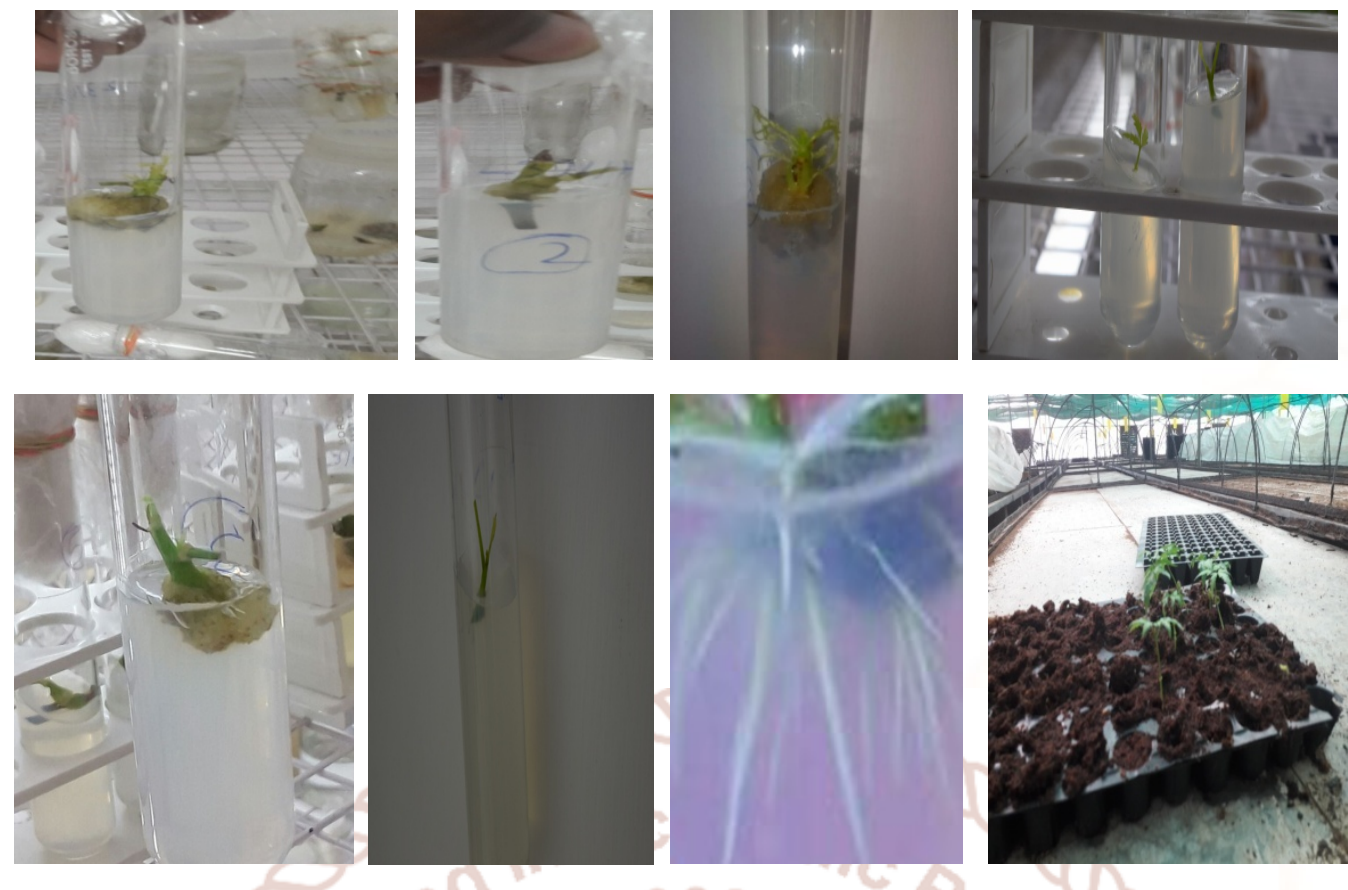

\section{Conclusion:-}

Most of the sample 6 out of 10 contaminated by fungus, during rainy season it is very difficult to inoculate explant in India. Only out of 10 four sample survived, out of which one was control. New way of sterilization protocol required for inoculation of Azadirachta indica. Callus observed in the 3 samples and by further treatment with Cytokinin and Auxin, growth of shoot and root observed.Appropriate growth of shoot and leaves observed after treating with Kinetin . Later for rooting IBA at concerntration of $15 \mu \mathrm{l} / 100 \mathrm{ml}$ is used and growth of root observed.Further experiment can be continued by taking these two plant hormones, to initiate root and shoot from callus of Azadirachta indica.

\section{Acknowledgements:-}

Special thanks to Dr. Animesh Sinha, Senior scientist ( Institute Of Forest Productivity, Lalgutwa, Ranchi ) for special guidance regarding handling procedure of explant and special thanks to Yaminee, Neha and Devendra trainee in ABLR, Raipur assist me in this project.

\section{References:-}

1) Allan, E.J., Eeswara, J.P., Johnson, S., Mordue (Luntz), A.J., Morgan, E.D. and Stuchbury, T. (1994) The production of azadirachtin byin vitro tissue culture extracts of neem,Azadirachta indica. Pestic. Sci. 42:147-152.
2) B.Venkateswarulu, Tissue culture technology for propagation of elite neem tree,SAIC News letter,March,1996.

3) Eeswara,J.P.Stuchbury,Allan,E.J.Mordue,A.J.A standard procedure for the micro propagation of neem tree (Azadirachta indica A..Juss.) Plant cell reports v.17.p.215-219,1998.

4) Narayan, P.Jaiswal.V.S. Plantlet regeneration from leaflet callus of Azadirachta indica A.Juss. Journal of Tree Science, v.4.n.1.p.65-68,1985.

5) R.Chaturvedi,M.K. Razdan, S.S.Bhojwani, Production of haploids of neem (Azadirachta indica A.Juss) by another culture, Plant cell Rep.21(2003)- 531-537.

6) Ramesh, K. and Padhya, M.A. (1990)In vitro propagation of neem, Azadirachta indica (A. Juss.), from leaf discs.Ind. J. Exp. Biol. 28(10):932-935.

7) Rangaswamy, N.S. and Promila (1972) Morphogenesis of the adult embryo ofAzadirachta indica A. Juss. Z.Pflanzenphysiol. 61:371-319.

8) Rao, M.V.S., Rao, Y.V., Rao, Y.S. and Manga, V. (1988) Induction and growth of callus inAzadirachta indica (A. Juss.).Crop Improv. 15:203-205.

9) Reddy, A.R.; BAVAJI, M.; Rao, J.V.S. Micropropagation of Azadirachta indica A. Juss.via cotyledonary nodes. Indian Journal of Biothechnology, v.5, p.309-311, (2009). 
10) Shahin-Uz-Zaman, M. Arafuzzashman, M.Haque, M.S. Luna, L.N. In vitro clonal propagation of the neem tree (Azadirachta indica A. Juss.). African Journal of Biotechnology, v.7, n.4, p.386391,(2008).

11) Sharuti Verma, Kuldeep Yadav and Narendra Singh (2011), Optimization of the protocols for surface sterilization, regenaration and acclimatization of Stevia rebaudiana,Bertoni;American-Eurasian J.Agric and Environ. Sci.11:221-227.

12) T.Murishage ,F.Skoog,A revised medium for rapid growth and bioassays with tobacco cultures, Physiol Plant 15 (1962) 473-497.

13) Wewetzer 1998, Callus Culture of Azadirachta indica and their potential for the production of azadirachtin. Phytoparasitica 26(I);47-52.

14) Y.C.Tripathi Neem-A veratile gift of nature, Everyman's sci,33 (1998),55. 